\title{
Study on the Elimination of Angiostrongylus costaricensis First Stage Larvae in the Experimental Infection of Swiss Mice
}

\author{
Cibele Canali, Aline H Goulart, Carlos Graeff-Teixeira ${ }^{+}$
}

\begin{abstract}
Laboratório de Parasitologia, Curso de Pós-Graduação em Biociências, Instituto de Biociências, Faculdade de Medicina, PUCRS, Av. Ipiranga 6681, 90619-900 Porto Alegre, RS, Brasil
\end{abstract}

\begin{abstract}
Abdominal angiostrongylosis is a nematode infection of wild rodents. Human infection may result in severe abdominal disease and has been reported from several countries in the Americas. The domestic mouse, Mus musculus, has not been found with natural infection and, like other urban rodents, should not be considered a natural host for Angiostrongylus costaricensis. Quantification of parasitic forms released for transmission may better express the coevolutionary status in parasite-host relationship. With this objective, five groups of experimentally infected Swiss mice were followed for up to 155 days post-infection (PI) days and the quantification of first stage larvae (L1) output revealed: an irregular elimination of $L 1$ and a huge variation in the patency period (1 to 114 days) and in the number of L1 eliminated daily by individual animals (1 to $6340 \mathrm{Ll} / \mathrm{g}$ ). Overall mortality was $72 \%$ (range: $28 \%$ to $100 \%)$ at seven weeks PI. In conclusion, abdominal angiostrongylosis in M. musculus presents high mortality and a very variable and irregular elimination of $L 1$ in feces.
\end{abstract}

Key words: Angiostrongylus costaricensis - abdominal angiostrongylosis - Mus musculus - coevolution

Angiostrongylus costaricensis Morera and Céspedes, 1971, is a parasitic nematode of rodents and molluscs are the intermediate hosts (Morera 1973). Human disease has been reported from most countries in the Americas (Pena et al. 1995). Wild rodents, like Sigmodon hispidus in Costa Rica and Oryzomys nigripes (Olfers, 1818) in southern Brazil, have been identified as the natural definitive hosts (Morera 1973, Graeff-Teixeira et al. 1989). Sinantropic rodents, like the domestic mouse Mus musculus (Waterhouse, 1837) have not been found with natural infection and the high mortality observed in the experimental infection with A. costaricensis has been taken as one explanation for the lack of documentation of naturally infected animals (Morera 1985, Santos et al. 1996). Coevolution status in parasite-host pairs has been classically expressed by direct effects of virulence of the parasite or reactivity of the host (morbidity or mortality). An alternative approach is centered in the quantification of parasitic forms made available for transmission along time, represented by the area (Ao) beneath the titer-time curve (Garnik 1992).

Financial support CNPq 500893.92-6, PUCRS, PIBICCNPq (CC, AHG) and PP IIB CNPq (CGT).

${ }^{+}$Corresponding author. Fax +55-51-320.3500 (R 4144). E-mail graeteix@music.pucrs.br

Received 12 June 1997

Accepted 5 November 1997
We describe some aspects of the kinetics of elimination of $A$. costaricensis' first stage larvae (L1) in feces of Swiss mice that further illustrate the lack of adaptation of this rodent to the etiological agent of abdominal angiostrongylosis.

\section{MATERIALS AND METHODS}

The A. costaricensis "Santa Rosa" strain has been mantained in the laboratory since 1992 with sucessive infections of Swiss M. musculus and the veronicelid slug Phyllocaulis soleiformis (D'Orbigny, 1835). Isolation of infective third stage larvae (L3) was performed as previously described (Graeff-Teixeira \& Morera 1995). Five groups of Swiss mice were inoculated with eight L3 into the stomach with a metallic cannula. The number of animals in each group $(7,7,7,10,12)$ varied according to the number of $\mathrm{L} 3$ available for infection. From the 21st day post-infection (PI), a sample of feces was individually collected every day up to 155 days post-infection (PI) and larvae were counted after their isolation with the Baermann method. Regularity of elimination was expressed by a ratio (PO, Patency/Observation) of the sum of days with larvae excretion (patency period) and total days of observation for individual animals. "Ao" is defined by the sum of daily larval output for individual animals, as proposed by Garnik (1992).

\section{RESULTS}

Mortality increased from the 4th week PI and varied from $28.5 \%$ to $100 \%$, with a overall mor- 
tality at seven weeks PI of $72 \%$ (Fig. 1). Twelve out of the 43 mice were alive after the 30th PI day: 3 died at 32, 25 and 27 PI day, while a number were sacrificed: 4 at 33rd PI and 5 at 155th PI day, without the identification of intra-arterial worms at necropsy. A large variability was seen with the patency period (1 to 114 days) and the PO ratio (0.03 to 1.00 ) (Fig. 2). Only 16 out of 43 animals $(37.2 \%)$ presented with a $\mathrm{PO}>0.5$ and $11(25.5 \%)$ had a $\mathrm{PO}>0.8$. Curves of frequencies for days of patency, $\mathrm{PO}$ ratio and survival days were deviated to the left, showing higher frequencies in categories of lower values (Fig. 2).

The daily elimination of $\mathrm{L} 1$ by individual mice varied from one $\mathrm{L} 1 / \mathrm{g}$ feces to $6340 \mathrm{~L} 1 / \mathrm{g}$ feces. Three patterns of curve were seen in graphics representing the daily individual larval output: early $(5 / 29-17.2 \%)$, late $(13 / 29-44.8 \%)$, continuous (11/29 - 37.9\%), L1 elimination (Fig. 3). In six animals the larval output was very low and eight mice did not eliminate L1. The Ao was individually calculated and varied from zero to 92982 (medium 3959.1; standard deviation 13727.12; variance: 188433714). The medium Ao in each group varied from 17.2 to 13236.6. The huge variation in most of the data was similar among the five groups inoculated with different larvae isolates.

\section{DISCUSSION}

Both from epidemiological field work and from experimental studies there are indications that the main definitive hosts for A. costaricensis are wild rodents (Tesh et al. 1973, Morera 1985, GraeffTeixeira et al. 1989, Santos et al. 1996). Sinantropic or urban rodents, like M. musculus, Rattus norvergicus (Linnaeus, 1758) and Rattus rattus (Linnaeus, 1758) probably do not play an
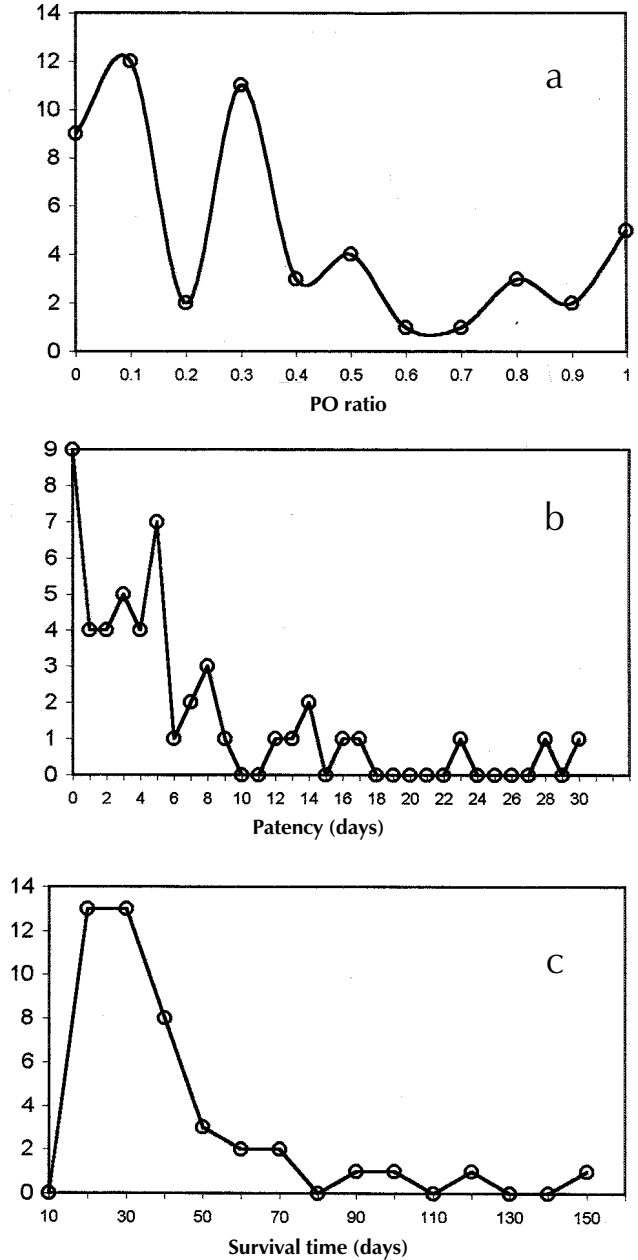

Fig. 2: distribution of frequencies for (a) PO ratio, (b) number of days with larvae elimination (patency) and (c) survival time in five groups of Swiss mice experimentally infected with Angiostrongylus costaricensis.

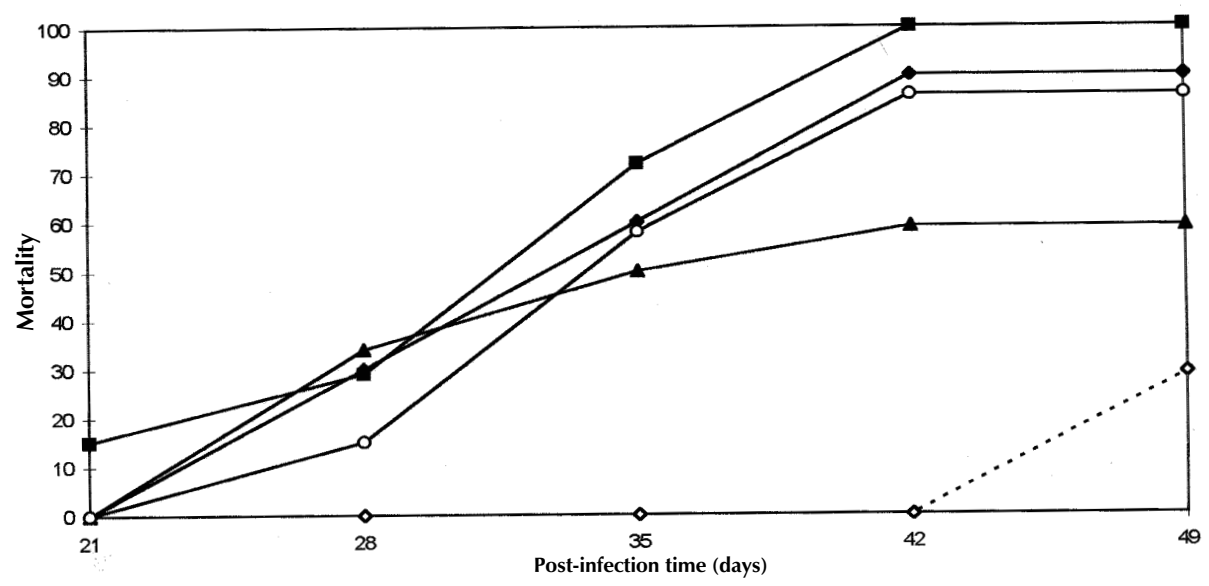

Fig. 1: mortality (\%) along time post-infection in five groups of Swiss mice experimentally infected with Angiostrongylus costaricensis (Santa Rosa strain). 

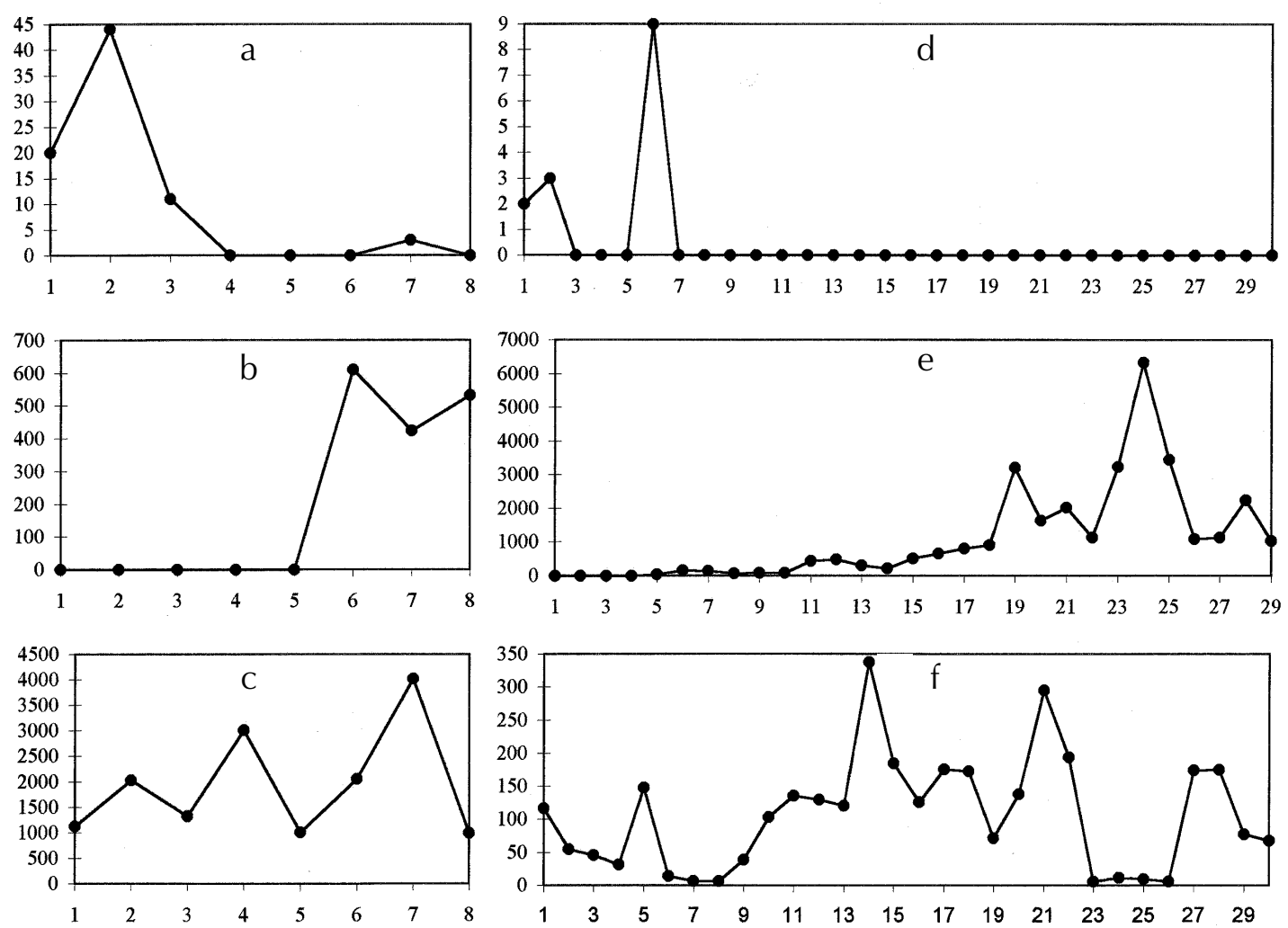

Fig. 3: examples of graphics representing curves of first stage larvae fecal elimination ("y” axis) in individual Swiss mice with short $(a, b, c)$ or long (d, e, f) survival time (days, "x" axis). Three main patterns can be depicted: early (a, d), late (b, e) or continuos and irregular (c, f) larval daily output.

important role as hosts for this metastrongylid worm, as reviewed by Santos et al. (1996). Many confirmed human infections have been detected in small towns with a rural-like enviroment, where the sinanthropic rodents may have opportunities to contact the parasite in its wild cycle. Not a single case was been documented among residents at large urban areas, that are usually inadequate environments for the presence of molluscs and by consequence, to the transmission of the parasite (Rambo et al. 1997).

The classical wisdom about the characterization of adaptation in a host-parasite relationship put an emphasis in morbi-mortality of the host as descriptors for the coevolutionary status. An alternative and perhaps more universally applicable approach favors quantification of parasitic forms that are made available for transmission, like the L1 larvae eliminated in rodent feces in the $A$. costaricensis model. In graphics representing the daily larval output, like those of the Fig. 3, the area (Ao) beneath the curve would represent a quantitative assessment of coevolutionary status (Garnik
1992). This approach would have its best application in the comparative study of different host species and in the evaluation of their importance for the survival of a given parasite species. This report deals with a description of the kinetics of elimination of $A$. costaricensis' larvae in a common strain of laboratory mice.

The high albeit variable mortality is a well established feature of the experimental infection of mice strains, with the exception of C57BL/6 (Ishii $\&$ Sano 1989, Santos et al. 1996). Mice manifest disease (weight loss, diarrhea, hipoactivity) and most of the deaths occur from the 4th to the 6th week (Fig. 1) coincident with maturation of the worms. The incubation time (IT) in the human infection is unknown, but it may be similar to the observed IT in murine model.

Most animals survive less than 50 days, as can be seen in the distribution of frequencies of survival times (Fig. 2). Those with longer survival probably did not become infected or present an unisexual infection, as shown by Santos et al. (1996) and confirmed in the few animals that were 
sacrificed and had a post-mortem examination performed, in the present experiments. These data on morbi-mortality indicate that $M$. musculus is not well-adapted to A. costaricensis.

Besides Ao quantification (Garnik 1992), other detailed arrangement of the data, focusing especially the regularity of patent days (PO), the length of patent period and the individual daily larval output may contribute to a better characterization of host-parasite coevolutionary status. In these experiments, patent period was frequently short, the elimination of larvae was not regular and individual daily larval elimination was very variable.

Without a comparative analysis of Ao among several host species this index may loose power as indicator of coevolutionary status. However, intra-species observation of the shape of the curves of daily larval elimination brings some information (Fig. 3). The irregularity of L1 elimination was expressed not only by low values of PO ratio, but also by the diversity of curve shapes. Animals presenting the "early" pattern of larval output (Fig. 3a, b) or the "late" pattern (Fig. $3 \mathrm{c}$, d), even if they survive for a long period, they offer a limited contribution for transmission of the parasite. The "continuous" pattern (quantitatively expressed by the PO ratio) associated with the amount of L1 (expressed by Ao) would describe animals presenting the most important contribution to the maintenance of the parasite. This kind of detailed analysis is required specially in non-comparative studies like the present one. The isolated Ao quantification probably will help to rank different species or strains, according to degree of host-parasite adaptation. Experiments are underway to compare Ao determinations of several rodent species.

These results give further support to the idea that M. musculus is not a well-adapted host for $A$. costaricensis and to the conception of abdominal angiostrongilosis as a zoonosis with a primordial wild cycle.

\section{ACKNOWLEDGEMENTS}

To Eva Medeiros, for technical help.

\section{REFERENCES}

Garnik E 1992. Parasite virulence and parasite-host coevolution: a reappraisal. J Parasitol 78: 381-386.

Graeff-Teixeira C, Morera P 1995. Método para digestão de moluscos em ácido clorídrico para isolamento de larvas de metastrongilídeos. Biociências 3: 85-89.

Graeff-Teixeira C, Ávila-Pires FD, Machado RCC, Camillo-Coura L, Lenzi HL 1990. Identificação de roedores silvestres como hospedeiros do Angiostrongylus costaricensis no sul do Brasil. Rev Inst Med Trop São Paulo 32: 147-150.

Ishii AI, Sano M 1989. Strain dependent differences in susceptibility of mice to experimental Angiostrongylus costaricensis infection. J Helminthol 63: 302-306.

Morera P 1973. Life history and redescription of Angiostrongylus costaricensis Morera \& Céspedes, 1971. Am J Trop Med Hyg 22: 613-621.

Morera P 1985. Angiostrongyliasis abdominal: transmission y observaciones sobre su posible control, p. 230235. In Control y Erradicación de Enfermedades infecciosas: un simposio internacional OMS/OPS. Série de copublicaciones de la OPS no. 1.

Pena GPM, Andrade-Filho JS, Assis SC 1995. Angiostrongylus costaricensis: first record of its occurrence in the State of Espírito Santo, Brazil, and a review of its geographic distribution. Rev Inst Med Trop São Paulo 34: 369-374.

Rambo PR, Agostini AA, Graeff-Teixeira C 1997. Abdominal angiostrongylosis in southern Brazil - Prevalence and parasitic burden in mollusc intermediate hosts from eighteen endemic foci. Mem Inst Oswaldo Cruz 92: 9-14.

Santos FT, Pinto VM, Graeff-Teixeira C 1996. Evidences against a significant role of Mus musculus as natural host for Angiostrongylus costaricensis. Rev Inst Med Trop São Paulo 38: 171-175.

Tesh RB, Ackerman LJ, Dietz WH, Williams JA 1973. Angiostrongylus costaricensis in Panama. Prevalence and pathological findings in wild rodents infected with the parasite. Am J Trop Med Hyg 27: 348-356. 